\title{
DINÂMICA REGIONAL E GLOBALIZAÇÃO: espaços competitivos agrícolas no território brasileiro
}

\author{
Prof. Dr. Ricardo Castillo \\ Universidade Estadual de Campinas (UNICAMP) \\ Cidade Universitária ZeferinoVaz, 13083-970, Caixa Postal 6152, Campinas (SP), Brasil \\ Tel: (55 19) 3521.5114 - castillo@ige.unicamp.br \\ Prof. Dr. Samuel Frederico \\ sfrederico@unifal-mg.edu.br
}

\section{RESUMO}

As discussões teóricas que envolvem as noções de região e de rede têm sido das mais profícuas na história da produção do conhecimento sobre o espaço geográfico e a economia espacial, bem como para o avanço metodológico da Geografia. Esse campo semântico tem trazido grandes contribuições para o desvendamento da organização e do uso dos territórios. A partir da análise da modernização e expansão agrícola no território brasileiro, consideramos que os conceitos de região competitiva e logística, compreendidos como as expressões geográficas respectivamente da produção hegemônica e da circulação corporativa, podem dar conta da explicação da organização e do uso do território brasileiro no presente. Com essa proposta, esperamos dar uma pequena contribuição para o avanço teórico metodológico da Geografia e das ciências regionais.

Palavras-chave: Território brasileiro, produção agrícola moderna, região competitiva, logística

\begin{abstract}
This paper discusses the concepts of region and networks, as an important issue in Geography, Spatial Economy and Regional Sciences. It seems that the current space division of labour, known as globalization, commands new hegemonic ways of producing and circulating. We call this new geographic expressions competitive region and logistics. We search to demonstrate how operational these concepts are, through a study of the modernization and expansion of the agricultural fronts in the Brazilian territory.
\end{abstract}

Key words: Brazilian territory, modern agricultural production, competitive region, logistics

RÉSUMÉ

Les discussions théoriques sur les notions de région et de réseaux ont été les plus riches dans l'histoire de la production de la connaissance sur l'espace géographique et l'économie spatiale, ainsi que pour les avancées méthodologiques en Géographie. Ces notions contribuent à la réflexion sur l'organisation et l'utilisation des territoires. A partir de l'analyse de la modernisation et de l'expansion agricole sur le territoire brésilien, nous considérons que les concepts de région compétitive et de logistique, compris comme les expressions géographiques respectivement de la production hégémonique et de la circulation corporative, peuvent rendre compte de l'explication de l'organisation et de l'utilisation du territoire brésilien dans la période actuelle. Avec cette proposition, nous espérons contribuer à l'avancée théorique et méthodologique de la Géographie et des sciences régionales.

Mots-clés: Territoire brésilien, production agricole morderne, région compétitive, logistiqu

\section{INTRODUÇÃO}

Já é bastante corriqueiro o fato de que os fluxos de pessoas, bens e informação ganham em importância à medida que nos aproximamos do presente e adentramos no período histórico atual. Menos trivial, porém, é correlacionar esse fato com expressões geográficas e compartimentações regionais singulares, decorrentes da relação entre o aprofundamento da divisão territorial do trabalho e a ampliação dos circuitos espaciais produtivos.

Essa nova articulação entre redes e regiões se manifesta de variadas maneiras em diversas partes do mundo, podendo ser apreendida nas políticas territoriais dos Estados, através do planejamento, e nas estratégias das empresas, por meio de suas topologias (SANTOS \& SILVEIRA, 2001).

No território brasileiro, a modernização sofrida pela agricultura, principalmente a partir da década de 1970, e a expansão e consolidação de fronteiras agrícolas em áreas de Cerrado, têm causado perturbações nas noções tradicionais de região e de rede. Da análise dessa situação, decorre a 
constatação teórica da limitação do alcance explicativo de conceitos geográficos surgidos em momentos históricos anteriores e, em conseqüência, o reconhecimento da operacionalidade de propostas de renovação para apreender as principais variáveis do atual período, tal como em Santos (1988 e 1994), particularmente em relação às idéias de formação regional e circuito espacial produtivo, como componentes de uma teoria processual (B. S. SANTOS, 1988) mais ampla.

De nossa parte e com base na situação mencionada acima, propomos considerar os conceitos de região competitiva e logística, compreendidos de forma indissociável, como as expressões geográficas, respectivamente, da produção obediente a parâmetros internacionais de qualidade e custos e da circulação corporativa, objetivando dar conta da explicação da organização e do uso do território brasileiro no presente.

Partimos da concepção de que a competitividade não é um atributo circunscrito às empresas ou aos produtos no período da globalização, mas designa também uma condição dos lugares e regiões. A distribuição desigual de densidades materiais e normativas no território confere diferentes graus de competitividade às regiões para determinados tipos de produtos e, por conseguinte, a alguns agentes produtivos que nelas atuam e que delas fazem parte. Esse tem sido, aliás, o fundamento lógico e prático dos decantados Arranjos Produtivos Locais, clusters e congêneres, cuja profusão, com o apoio de poderes públicos locais, é notória, trazendo benefícios duvidosos para os lugares e prejuízos certos para o conjunto do território e da sociedade nacionais, como bem apontaram geógrafos (SANTOS, 1996) e economistas (BRANDÃO, 2007), ao mesmo tempo em que se revelam funcionais ao regime de acumulação vigente.

Quanto à noção de logística, preferimos não aderir à proposta de Ake Andersson (1986), para quem a História conheceu quatro revoluções logísticas, tendo a primeira ocorrido na Baixa Idade Média. A nosso ver, essa teoria dilui a força que o conceito pode ter como variável-chave do período técnico-científico-informacional (SANTOS, 1994). Como o nosso propósito é buscar operacionalidade para esse conceito, ainda que ao custo de uma manipulação que pode ser considerada reducionista, restringimos seu alcance temporal e espacial, empregando o termo para designar a manifestação hegemônica da circulação no período histórico atual, como ação exclusiva das empresas do circuito superior da economia (SANTOS, 1997).

A apreensão da realidade espacial, a cada momento histórico, exige renovação conceitual e mudanças de ordem teórica, sem as quais a produção do conhecimento corre o risco de se tornar inócua e a intenção de formular a crítica converte-se em discurso inoperante. Nesse sentido, as discussões que articulam as noções de região e de rede têm peculiar interesse para os estudos sobre o espaço geográfico e a economia espacial.

\section{UMA ARTICULAÇÃO DE CONCEITOS}

O ponto de partida para a explicitação de nossa concepção conceitual é a compreensão de que o espaço geográfico é um híbrido (LATOUR, 1994 e SANTOS, 1996) constituído pela combinação de coisas materiais (naturais e construídas historicamente) entre si e com as normas (sociais, políticas, jurídicas, econômicas, culturais) que regulam o uso, o acesso e a propriedade dessas coisas.

A partir dessa concepção de espaço geográfico pode-se dar significado e propor as necessárias articulações aos seus recortes, dando-lhes as condições para que se tornem instrumentos para a análise e para a interpretação das situações concretas, sendo, ao mesmo tempo, delas resultantes.

Dentre os principais compartimentos do espaço geográfico (território, região, lugar e paisagem), nos interessa, neste momento, apontar as especificidades da noção de região.

A região se expressa em diversas formas de compartimentação, sejam elas de cunho natural, histórico-cultural, administrativo ou econômico. Não é nosso propósito - nem seria de nossa competência - fazer um resgate desse conceito na história do pensamento geográfico . Interessa-nos apenas ressaltar que essas formas, surgidas historicamente e constantemente recriadas, coexistem, 
se sobrepõem e se articulam a cada momento da divisão territorial do trabalho. No presente, a exacerbação da especialização regional produtiva caracteriza um tipo de região funcional aos mercados internacionais (SANTOS, 1994). Trata-se de um compartimento produtivo do espaço geográfico, cujas forças de coesão se estabelecem, teoricamente, a partir de uma combinação de competências técnicas locais com interesses políticos distantes, cuja melhor designação parece ser a de região competitiva .

O período conhecido como globalização, assim, reproduz as segmentações políticas do espaço geográfico, particularmente a divisão do mundo em territórios nacionais, ao mesmo tempo em que faz emergir uma forma regional como expressão geográfica do novo paradigma produtivo. Disso decorre um grande aumento dos fluxos materiais e imateriais e uma ampliação dos circuitos espaciais (SANTOS, 1988, 1996; MORAES, 1991; ARROYO, 2001; SANTOS \& SILVEIRA, 2001; FREDERICO \& CASTILLO, 2004) de alguns produtos, fazendo da circulação um campo de atuação mais privilegiado do que em momentos anteriores.

A evidência desse expressivo aumento dos fluxos de mercadorias e de informação nas últimas décadas influenciou, de alguma maneira, a retomada dos estudos sobre as redes, na Geografia e fora dela (DIAS, 1995; 2005). A nebulosa conceitual que daí emerge exige alguma precisão na definição do termo, para que o nosso círculo de idéias se complete. Recorremos, mais uma vez, a Santos (1996), para afirmar que a rede é uma realidade material e social, ou seja, seu conteúdo ultrapassa sua dimensão geométrica (estruturas materiais que servem de suporte para os fluxos materiais e imateriais, de um ponto a outro de uma área) para alcançar uma dimensão geográfica. A partir dessa asserção, propomos que as redes são, a um só tempo, produto e circunstância social, suporte material e condição normativa da mobilidade espacial, traduzida analiticamente em termos de circulação e comunicação (RAFFESTIN, 1993), exercendo um papel fundamental na organização e no uso do território em diversas escalas. A rede é o instrumento técnico e político que viabiliza as estratégias de circular e de comunicar à distância.

\section{REGIÃO COMPETITIVA E LOGÍSTICA: EMBLEMAS DA GLOBALIZAÇÃO}

Como já sugerimos e a despeito de importantes teorias históricas que declaram o contrário, consideramos que a globalização expressa o atual período histórico. Resulta da afirmação do paradigma produtivo emergente na década de 1970 e do exponencial aumento dos fluxos materiais e informacionais, decorrente da gradativa mundialização da produção, da prestação de serviços e do consumo, pelo menos para alguns setores e circuitos econômicos (SANTOS, 1996 e 2000; BENKO, 1996; HIRST \& THOMPSON, 1998). A unicidade planetária das finanças, acompanhada por grande diversificação de formas e maior penetração nos tecidos sociais e na vida econômica, também é uma insígnia das transformações recentes do capitalismo (CASTILLO, 2008).

Junto a esse ideário, emerge com muita força e difunde-se rapidamente o sentencioso da competitividade que, pouco a pouco, deixa de ser um emblema somente das empresas, perpassa toda a sociedade e torna-se também um atributo dos lugares, das regiões e dos territórios. A competitividade deriva da articulação, em algumas frações do espaço, entre formas materiais (acessibilidade, infraestruturas produtivas, de circulação, comunicação, energia elétrica, abastecimento de água, sistemas de armazenamento, terminais multimodais e outras categorias de instalações e equipamentos, mais ou menos especializados) e normas (benefícios fiscais, outros incentivos a partir de recursos públicos locais, acordos entre instituições de pesquisa e empresas etc.) que garantem elevados níveis de produtividade e de fluidez.

Disso decorrem muitas coisas importantes. Por exemplo, o jogo entre as regiões desenvolvidas e subdesenvolvidas, matéria de tantas pesquisas e interpretações nas últimas décadas, coexiste, hoje, com manifestações locais e regionais, particularmente em países periféricos, que podem resultar naquilo que Araújo (2000) chamou de desintegração competitiva.

Mercator - volume 9, número 18, 2010: jan./abr. 
Dentre as manifestações geográficas emergentes nesse contexto, destacam-se: 1) o aprofundamento da especialização regional produtiva e 2) a grande carga de racionalidade que preside o movimento de mercadorias. Essas forças fazem parte, na verdade, de um mesmo processo e atuam sobre (e contra) a lógica, considerada "irracional", dos territórios. Desse embate entre uma lógica das redes e uma lógica dos territórios, resultam ilhas de eficiência produtiva, obedientes a parâmetros internacionais de qualidade e custos, e também corredores de fluidez material, em meio à viscosidade de vastas áreas, nas quais a mobilidade é precária ou mesmo inexistente.

Num esforço para ultrapassar as metáforas e chegar aos conceitos, propomos considerar as noções de região competitiva e logística como expressões, respectivamente, da produção hegemônica e da circulação corporativa, sem as quais a globalização, tal como a conhecemos, não existiria como período histórico.

O conceito de região competitiva deriva diretamente da idéia de coesão regional decorrente de vetores externos e fundamentada em arranjos organizacionais, proposta por Santos (1994) . Trata-se de um compartimento geográfico caracterizado pela especialização produtiva obediente a parâmetros externos (em geral internacionais) de qualidade e custos. Essas regiões, preferencialmente, são as que atraem os investimentos públicos e privados, transformando grandes porções do território em áreas de exclusão.

Assim, a idéia de região competitiva pode ser entendida como a expressão geográfica da produção na era da globalização. Parece-nos que este conceito permite dar conta de um amplo espectro de atividades econômicas, incluindo a agricultura, a indústria, os serviços e os casos mistos, como o agronegócio. As regiões competitivas, atreladas a determinadas atividades produtivas, coexistem com outros tipos de região, como as históricas e administrativas.

Aliás, em muitos casos, podemos nos defrontar com regiões históricas que adquirem, no período atual, atributos que a tornam competitiva, podendo vir a se caracterizar, por meio de decisões políticas, numa região administrativa. Um exemplo emblemático dessa hibridez se revela a partir da reivindicação de diversas associações de produtores de cafés diferenciados no Sul de Minas Gerais para a criação de selos de "Denominação de Origem". A Associação dos Produtores de Café da Mantiqueira, por exemplo, conseguiu o primeiro selo de origem para os cafés produzidos na "Região da Face Sulmineira da Serra da Mantiqueira", a exemplo dos vinhos franceses.

A “Denominação de Origem”, além de designar o local de produção do produto, também está relacionada às características naturais e culturais ímpares que, combinadas, conferem uma qualidade diferenciada ao produto. A denominação de origem do café se apropria das particularidades de uma região histórica, com uma identidade cultural própria, e fundamenta a criação de uma circunscrição administrativa para conferir maior competitividade a uma fração do espaço.

O território brasileiro possui inúmeros exemplos de regiões competitivas. Alguns dos casos mais contundentes são as regiões produtoras de commodities agrícolas. A exportação de grande parcela da produção, a presença de firmas transnacionais, a implantação de sistemas técnicos especialmente concebidos para viabilizar a produção, a especialização funcional das cidades locais são características comuns presentes na maioria dessas regiões.

Assim, a "região competitiva agrícola" pode ser entendida como um compartimento produtivo do espaço geográfico atrelado à produção agrícola moderna. São aquelas regiões cuja produção é hegemônica sobre as demais atividades, fazendo com que a região reúna uma forte densidade técnica (infra-estrutura de transporte e comunicação, sistemas de armazenamento, centros de pesquisa, agroindústrias) e normativa (desoneração fiscal, normas que facilitam o desembaraço das mercadorias, selos de denominação de origem etc.) vinculada à atividade agrícola dominante. Podemos elencar como regiões competitivas agrícolas as áreas produtoras de café (sul de minas, cerrado mineiro, sul da Bahia, leste de Rondônia), soja (Noroeste do Rio Grande do Sul, Norte do Paraná, diversas regiões de cerrado), laranja (interior paulista), cana-de-açúcar (interior paulista, avançando para o Sul de Minas, Triângulo Mineiro, centro e sudoeste goiano,), fruticultura irrigada (Vale do Rio São Francisco), Algodão (cerrado), flores (Holambra), uva (Rio Grande do Sul e Jundiaí/SP), 
apenas para mencionar as principais. Estas regiões se especializaram e ao mesmo tempo passaram a manter relações cada vez mais intensas dentro de circuitos espaciais produtivos agrícolas que extrapolam o próprio país.

A tabela 1 dá uma idéia da concentração regional de alguns produtos para o conjunto do território brasileiro.

Tabela 1- Brasil. Concentração da produção agrícola. Produtos selecionados. 2005

\begin{tabular}{|c|c|c|c|c|c|c|c|}
\hline \multirow{2}{*}{ Produto } & \multicolumn{3}{|c|}{ Quantidade de municípios } & \multicolumn{2}{|c|}{$\begin{array}{l}\text { UF de maior } \\
\text { participação }\end{array}$} & \multicolumn{2}{|c|}{ Região de maior participação } \\
\hline & $10 \%$ & $25 \%$ & $50 \%$ & UF & $\%$ & Região & $\%$ \\
\hline Algodão herbáceo & 2 & 4 & 15 & MT & 36,6 & $\mathrm{CO}$ & 63 \\
\hline Soja & 4 & 16 & 69 & MT & 34,7 & $\mathrm{CO}$ & 56 \\
\hline Cana-de-açúcar & 12 & 41 & 124 & SP & 60,2 & SE & 69 \\
\hline Arroz & 4 & 12 & 49 & RS & 46,2 & $\mathrm{~s}$ & 55 \\
\hline Laranja & 2 & 7 & 21 & SP & 80,4 & SE & 84 \\
\hline Café & 10 & 39 & 176 & MG & 46,8 & SE & 82 \\
\hline
\end{tabular}

Fonte: IBGE - Produção Agrícola Municipal

Elaboração própria.

Quando se constata que o território brasileiro possui 5.564 municípios (IBGE, 2005), pode-se ter uma idéia mais precisa do grau de concentração espacial produtiva mostrado na tabela acima. Esse fenômeno se repete para alguns setores da atividade industrial e para algumas categorias de serviços.

Um dos atributos que a região necessita ter para se tornar competitiva é dispor de uma eficiente logística. Com as mudanças ocorridas no paradigma produtivo a partir da década de 1970 (HARVEY, 1992; BENKO, 1996), a noção de logística passou a ser um dos pontos centrais do ordenamento dos fluxos que perpassam os diversos circuitos espaciais produtivos. A idéia de logística, na migração do sentido militar para o empresarial, tornou-se um termo polissêmico, empregado para designar variadas formas de prestação de serviços, condições gerais de produção, setor de atividade econômica e ramo de investimentos públicos. Na tentativa de compreender o termo em sua dimensão geográfica, propomos defini-lo como o conjunto de competências infra-estruturais (transportes, armazéns, terminais multimodais, portos secos, centros de distribuição etc.), institucionais (normas, contratos de concessão, parcerias público-privadas, agências reguladoras setoriais, tributação etc.) e operacionais (conhecimento especializado detido por prestadores de serviços ou operadores logísticos) que, reunidas num subespaço, podem conferir fluidez (ARROYO, 2001; 2005) e competitividade aos agentes econômicos e aos circuitos espaciais produtivos. Trata-se da versão atual da circulação corporativa (CASTILLO, 2007 e 2008).

Consideramos assim que a região competitiva e a logística são duas das expressões geográficas mais contundentes da globalização e revelam, de alguma forma, a lógica da aceleração contemporânea (SANTOS, 1996).

\section{ESPECIALIZAÇÃO REGIONAL PRODUTIVA E AMPLIAÇÃO DE CIRCUITOS ESPACIAIS AGRÍCOLAS NO TERRITÓRIO BRASILEIRO}

Nos anos 1960, o uso agrícola do território brasileiro sofreu profundas transformações. Os eventos mais marcantes que alteraram a sua organização foram: o aprofundamento das relações entre a agricultura e as atividades urbano-industriais; a introdução de novos sistemas técnicos agrícolas (RAMOS, 2001), incluindo inovações mecânicas, físico-químicas e biológicas; a internalização da indústria de insumos agrícolas, como parte da política de "substituição de importações"; a diversificação da pauta exportadora; a redução das importações de produtos agrícolas; e a expansão da fronteira agrícola moderna (MAZZALI, 2000).

Mercator - volume 9, número 18, 2010: jan./abr. 
A situação geográfica emergente, decorrente das alterações na dinâmica agrícola, caracteriza a difusão do meio técnico científico no campo brasileiro, com forte financiamento e participação, naquele primeiro momento, do Estado. A agricultura brasileira se tornou cada vez mais subordinada ao capital monopolista, devido ao aumento do poder das empresas multinacionais produtoras de insumos e equipamentos agrícolas. As grandes corporações determinaram os novos padrões tecnológicos e subordinaram os produtores à sua lógica. Os pequenos agricultores passaram a ter cada vez menos chances de sobrevivência diante da impossibilidade de adquirir os novos sistemas técnicos e acompanhar, na mesma velocidade, um novo tempo que se implantava no território (FREDERICO, 2009).

A modernização e a expansão da agricultura no território brasileiro permitem distinguir, de maneira simplificada, duas grandes regiões de produção agrícola: os belts e as fronteiras agrícolas modernas. Os belts, segundo Santos e Silveira (2001), constituem as áreas tradicionais de produção agrícola, reunindo, resumidamente, os estados da região Sul, São Paulo e a metade mais ao sul de Minas Gerais. Nestas áreas, encontramos uma divisão territorial do trabalho mais aprofundada, nas quais a produção agrícola moderna convive e se inter-relaciona com um grande número de outras atividades econômicas. A ocupação mais antiga dessas áreas faz com que o território apresente um número maior de heranças físico-territoriais e sócio-políticas, tornando mais complexas as relações. Nos belts agrícolas, a terra disponível para a expansão da agricultura se encontra praticamente esgotada e os círculos de cooperação estabelecidos nos circuitos espaciais produtivos agrícolas envolvem uma grande diversidade de agentes. Nestas áreas, por exemplo, encontramos uma participação mais ativa e proeminente das cooperativas, o que demonstra uma maior organização dos produtores, fruto de uma construção histórica.

Já as áreas de fronteira agrícola consolidada e em expansão (Frederico, 2009) reúnem características particulares que, num contexto de globalização econômica, as tornam mais aptas a receber o novo de maneira menos resistente, constituindo condições geográficas ideais para a política das grandes empresas, para além do processamento industrial e da comercialização. De um lado, as características edafo-climáticas e a topografia e, de outro, a grande concentração fundiária, a urbanização especializada e dispersa, a baixa densidade em infra-estruturas, a distância em relação aos centros dinâmicos de consumo do mercado interno e aos portos exportadores e um vasto estoque de terras ainda a ser ocupado pelo agronegócio, criaram possibilidades inéditas para a atuação de grandes empresas.

Nas fronteiras agrícolas modernas, o desenvolvimento e a expansão dos sistemas técnicos permitiram explorar os recursos naturais por meio da utilização dos fundos territoriais (MORAES, 2000; 2002), aproveitando as características fisiográficas favoráveis do Cerrado e promovendo a integração do território através de sua ocupação mais efetiva .

Milhões de hectares de domínio dos Cerrados (principalmente porções do Centro Oeste e do Nordeste, mais ou menos coincidentes com o chamado polígono dos solos ácidos) vêm sendo ocupados, desde a década de 1970, por uma agricultura moderna praticada em imensas propriedades. Essa agricultura é, por um lado, grande consumidora de insumos (químicos e tecnológicos), implementos (sobretudo maquinário), crédito (oficial e privado) e assistência técnica especializada e, por outro, grande produtora de commodities agrícolas, ao custo da retirada da cobertura vegetal original e também substituindo pastagens e formas tradicionais de cultivo, com a expulsão de pequenos produtores.

Desde meados dos anos 1980, o papel articulador da modernização agrícola, antes exercido quase que exclusivamente pelo Estado, vai sendo compartilhado, aos poucos, com grandes empresas agroindustriais e tradings, nacionais e estrangeiras (MAZZALI, 2000). Na esteira do discurso e da prática neoliberais, o setor agrícola moderno no Brasil vive hoje uma nova regulação (ANTAS JR., 2005), que aprofunda características que vinham sendo gestadas desde o período anterior (CASTILLO, 2004 e 2005). 
No sentido de melhor apreender essas transformações, parece cada vez mais importante reconhecer a interação entre três variáveis que se destacam na conformação da agricultura científica globalizada (SANTOS, 2000) no território brasileiro: 1) a modernização e expansão da agricultura moderna no território brasileiro; 2) a emergência de regiões competitivas, tanto nas áreas produtoras tradicionais (belts) quanto nas áreas de fronteira agrícola moderna (fronts); e 3) a predominância, no plano das idéias e também das ações, bem como nas políticas públicas e privadas, da logística.

A demanda por logística tem aumentado exponencialmente, nas últimas duas décadas, com a emergência de regiões competitivas e a afirmação dos circuitos espaciais produtivos, tornando-a um subsetor estratégico (NOVAES, 2001; CAIXETA-FILHO, 2001; NAZÁRIO, WANKE \& FLEURY, 2006; OJIMA, 2006). Se compreendida como a expressão atual da circulação corporativa, tal como já sugerimos, a logística ajuda a racionalizar, otimizar, em cada território, o uso da combinação de técnicas avançadas com técnicas mais ou menos precárias, interligando espaços competitivos da produção aos centros dinâmicos de consumo.

\section{REGIÃO COMPETITIVA E VULNERABILIDADE (ALGUNS CASOS)}

A expansão da cana-de-açúcar em áreas de fronteira consolidada com grãos serve para ilustrar as conseqüências perversas da especialização produtiva no campo e sua urbanização funcional, gerando um fenômeno que já foi chamado de cidades do agronegócio (ELIAS, 2007). A Prefeitura do município de Rio Verde (GO), com o apoio de 47 entidades de classe, criou uma lei que limita em 10\% da área municipal destinada à agricultura, o cultivo da cana, sob a alegação de colocar em risco os investimentos já realizados e futuros vinculados às cadeias produtivas da soja e do milho (agroindústrias de óleo e farelo, frigoríficos, armazéns, criação de aves e suínos principalmente) .

Outro exemplo é a crise deflagrada na cafeicultura no início de 2009. A combinação entre a elevação do preço dos insumos nos últimos anos (500\% nos últimos 10 anos) e o baixo preço ofertado à saca do café (cresceu pouco mais de $20 \%$ no mesmo período) fez com que organizações ligadas direta ou indiretamente ao circuito do café (Conselho Nacional do Café, Federação da Agricultura do Estado de Minas Gerais, OCEMG Sescoop/MG e SICOOB Sistema Crediminas) criassem no Sul de Minas o "Movimento SOS Cafeicultura". No mês de janeiro de 2009, houve 158 mil demissões no estado de Minas Gerais, sendo que as cidades do Sul de Minas estão entre as que mais demitiram, segundo dados do Ministério do Trabalho. Grande parte das demissões está ligada direta ou indiretamente à economia cafeeira, segunda principal atividade exportadora do Estado. O "Movimento SOS Cafeicultura" realizou, em março de 2009, uma manifestação na cidade de Varginha que, segundo dados dos organizadores, reuniu 25 mil pessoas, com ampla divulgação na mídia regional. As organizações e produtores reivindicam uma maior participação do Estado na atenuação da crise por meio da garantia de preço mínimo aos produtores, da transformação da dívida financeira dos cafeicultores em dívida de produto, da redução dos juros e do aumento de crédito para os produtores, além de um maior investimento em imagem do café.

Ambos os casos ilustram a vulnerabilidade de regiões funcionais atreladas aos mercados internacionais, sempre sujeitas a fatores externos que não podem controlar e nem mesmo prever.

No caso das áreas de fronteira, a especialização regional produtiva, além de implicações de ordem local (ambiental, econômica, social, política), também repercute na escala nacional através da geração de fluxos de grande volume e baixo valor agregado, numa porção do território distante dos centros consumidores e portos e desprovida de condições logísticas capazes de fazer frente às quantidades produzidas (medidas em dezenas de milhões de toneladas a cada safra).

São claros os círculos de cooperação estabelecidos entre as grandes empresas do agronegócio (Cargill, Bunge, ADM, Maggi, Coinbra, Caramuru, entre outras), as empresas de logística (ALL, CVRD, Hermasa etc.) e o Estado. 
Essas grandes empresas do agronegócio dominam, cada vez mais, o beneficiamento (classificação, limpeza, secagem), a assistência técnica, o processamento agroindustrial, o mercado de fertilizantes, o mercado de sementes, o armazenamento, o financiamento da produção, a comercialização e a exportação. Controlam indústrias processadoras, armazéns e silos, empresas de colonização, empresas de comercialização de produtos agrícolas e seus derivados; atuam no transporte rodoviário, ferroviário, fluvial e marítimo, possuem terminais em portos fluviais e marítimos, centros de distribuição, escritórios exportadores, postos avançados de compra de grãos; fornecem crédito de custeio e investimento, prestam assessoria técnica a produtores conveniados, estabelecem parcerias com empresas de logística entre outras ações que variam segundo as especificidades do circuito de cada produto (os complexos soja, algodão, laranja, café e cana-de-açúcar estão entre os mais importantes).

Desse tipo de modernização, decorre uma geografia adaptada aos ditames da globalização, ao custo, muitas vezes, do bem-estar das populações locais.

Além da vulnerabilidade política, econômica, militar e financeira, a formação sócio-espacial brasileira padece também de uma crescente vulnerabilidade territorial. Às implicações de uma excessiva reunião de fatores produtivos numa porção do território, com pouca ou nenhuma autonomia decisória regional (o que produzir, de que maneira e em quais quantidades), soma-se o risco de imobilizar grandes quantidades de capital em complexos sistemas de engenharia a serviço de monoculturas de exportação que podem tornar-se ociosas por conta de oscilações dos mercados e dificultar reconversões produtivas (CASTILLO, 2005). Nesse passo, a disputa entre lugares e regiões por investimentos públicos e privados tende a aumentar, gerando produção desnecessária e circulação desnecessária (SANTOS \& SILVEIRA, 2001), minando o federalismo brasileiro e fragmentando o território.

\section{CONSIDERAÇÕES FINAIS}

À forma histórica atual da divisão territorial do trabalho corresponde uma forma, também historicamente determinada, de circulação. Entendemos que a região competitiva e a logística são termos que expressam adequadamente essas duas importantes manifestações geográficas do presente.

Isso nos obriga a reconhecer a existência de uma lógica dos territórios e uma lógica das redes, de cujo embate permanente criam-se e recriam-se distintos modos de produzir e de circular, que coexistem de forma articulada e conflituosa, disputando espaços e recursos. A logística somente ganhou importância e se constituiu como setor de atividade econômica justamente porque os territórios, entendidos como totalidade, são, do ponto de vista dos capitais mais modernos, irracionais, uma vez que resultam da interação entre muitos agentes e do confronto entre diversos interesses.

Essa "irracionalidade" assim definida se exprime, por exemplo, nas passagens em nível, invasões de domínios ferroviários, rodovias precárias, caminhões circulando com sobrepeso, frete rodoviário mantido artificialmente baixo, hidrovias sem sinalização, portos assoreados e de baixo calado, mas também nos produtores agrícolas recalcitrantes, nos movimentos sociais de luta pela reforma agrária e no amplo espectro do circuito inferior da economia urbana (SANTOS \& SILVEIRA, 2001), frequentemente criminalizado e considerado nocivo aos grandes negócios. Superar esses "gargalos logísticos" e promover uma urbanização funcional às atividades agrícolas modernas tornaram-se objetivos de Estados e empresas, como condição para inserir-se de forma competitiva nos mercados internacionais.

A noção tradicional de região e a velha geografia dos transportes não dão conta de explicar essa situação, exigente de uma renovação conceitual capaz de superar tanto os discursos coniventes quanto as críticas desprovidas de análise. 


\section{REFERÊNCIA BIBLIOGRÁFICA}

ANDERSSON, Ake. The four logistical revolutions. Papers in Regional Science, v. 59, p. 1-12, 1986

ANTAS JR., Ricardo Mendes. Território e regulação: espaço geográfico, fonte material e não-formal do direito. São Paulo: Humanitas/FAPESP, 2005.

ARAUJO, Tânia Bacelar. Dinâmica regional brasileira nos anos noventa: rumo à desintegração competitiva. In: CASTRO, I. E. et al. (org.). Redescobrindo o Brasil: 500 anos depois. Rio de Janeiro: Bertrand Brasil, 2000, p. 73-89.

ARROYO, Mónica. Território nacional e mercado externo: uma leitura do Brasil na virada do século XX. 2001. 250 f. Tese (Doutorado em Geografia Humana). Faculdade de Filosofia, Letras e Ciências Humanas da Universidade de São Paulo, São Paulo, 2001.

ARROYO, Mónica. Fluidez e porosidade do território brasileiro no contexto da integração continental. In: SILVEIRA, M. L. (org.). Continente em chamas: globalização e território na América Latina. Rio de Janeiro: Civilização Brasileira, 2005. p. 211-242.

ARROYO, Mónica. A economia invisível dos pequenos. Le Monde Diplomatique Brasil, p. 30-31, outubro de 2008.

BENKO, George. Economia, espaço e globalização na aurora do século XXI. São Paulo: Hucitec, 1996.

BRANDÃO, Carlos. Território e desenvolvimento: as múltiplas escalas entre o local e o global. Campinas: Editora da Unicamp, 2007.

CAIXETA-FILHO, José Vicente \& GAMEIRO, A. H. (orgs.). Transporte e logística em sistemas agroindustriais. São Paulo: Atlas, 2001.

CASTILLO, Ricardo. Transporte e logística de granéis sólidos agrícolas: componentes estruturais do novo sistema de movimentos do território brasileiro. Investigaciones Geográficas - Boletin del Instituto de Geografia, UNAM, p. 79-96, $\mathrm{n}^{\circ}$ 55, 2004.

CASTILLO, Ricardo. Exportar alimentos é a saída para o Brasil? O caso do complexo soja. In: ALBUQUERQUE, E. S. (org.). Que país é esse? Pensando o Brasil contemporâneo. São Paulo: Ed. Globo, 2005. p. 283-306.

CASTILLO, Ricardo. Logística e consolidação de fronteiras agrícolas no território brasileiro Anais. XI Encontro de Geógrafos da América Latina. Bogotá D.C., Colômbia, 26 a 30 de março de 2007.

CASTILLO, Ricardo. Sustentabilidade, globalização e desenvolvimento. In: OLIVEIRA, M. P. et al. (org.). O Brasil, a América Latina e o mundo: espacialidades contemporâneas. Rio de Janeiro: Anpege / Clacso / Faperj / Lamparina, 2008. p. 401-410.

CORREA, Roberto Lobato. Região e organização espacial. São Paulo: Ática, 1987. 93 p.

DIAS, Leila C. Redes: emergência e organização. In: CASTRO, I. E. et al. (orgs.). Geografia: conceitos e temas. Rio de Janeiro: Bertrand Brasil, 1995. p. 141-162.

DIAS, Leila C. Os sentidos da rede: notas para discussão. In: DIAS, L. \& SILVEIRA, R. L. L. (orgs.). Redes, sociedades e territórios. Santa Cruz do Sul: Edunisc, 2005. p.11-28.

ELIAS, Denise. O meio técnico-científico-informacional e a reorganização do espaço agrário nacional. In: MARAFON, G. J. et al. (org.). Abordagens teórico-metodológicas em geografia agrária. Rio de Janeiro: Editora da Uerj, 2007. p. 49-66.

FREDERICO, Samuel; CASTILLO, Ricardo. Circuito espacial produtivo do café e competitividade territorial no Brasil. Ciência Geográfica, Bauru, X, Vol. X - (3), p. 236-241, set. / dez de 2004.

FREDERICO, Samuel. O Novo Tempo do Cerrado: Expansão dos Fronts Agrícolas e Controle do Sistema de Armazenamento de Grãos. 2009. 273 f. Tese (Doutorado em Geografia Humana). Faculdade de Filosofia, Letras e Ciências Humanas da Universidade de São Paulo. São Paulo, 2009.

GIORDANO, Samuel R. Competitividade regional e globalização: o agronegócio da soja brasileira nos anos 90. Campinas, SP: Akademica Editora, 2005. 175p.

HARVEY, David. A condição pós-moderna: uma pesquisa sobre as origens da mudança cultural. São Paulo: Loyola,1992. 349 p. 
HIRST, Paul; THOMPSON, G. Globalização em questão: a economia internacional e as possibilidades de governabilidade. Petrópolis: Vozes, 1998. 364 p.

LATOUR, Bruno. Nous n'avons jamais été modernes: essai d'anthropologie synétrique. Paris: La Découverte, 1994. $213 \mathrm{p}$.

LENCIONI, Sandra. Região e geografia. São Paulo: Editora da Universidade de São Paulo, 1999. 214 p.

MAZZALI, Leonel. O processo recente de reorganização agroindustrial: do complexo à organização em rede. São Paulo: Editora UNESP, 2000. 175 p.

MORAES, A. C. R. Los circuitos espaciales de la producción y los círculos de cooperación en el espacio. In: YANES, L. et al. (org.). Aportes para el estúdio del espacio socioeconômico, tomo III, El Colóquio. Buenos Aires: [s.n.], 1991.

MORAES, A. C. R. Bases da formação territorial do Brasil: o território colonial brasileiro no "longo" século XVI. São Paulo: Hucitec, 2000. 431 p.

MORAES, A. C. R. Território e história no Brasil. São Paulo: Hucitec, 2002. 198 p.

NAZÁRIO, P., WANKE, P.; FLEURY, P. F. O papel do transporte na estratégia logística. COPPEAD. [On line]. Universidade Federal do Rio de Janeiro, 2000. Disponível em: $<$ http://www.cel.coppead.ufrj.br/ fs-public.htm> [25 de janeiro de 2008].

NOVAES, Antonio G. Logística e gerenciamento da cadeia de distribuição: estratégia, operação e avaliação. Rio de Janeiro: Campus, 2001. 409 p.

OJIMA, Andréa L. R. O. Perfil da logística de transporte de soja no Brasil. Informações Econômicas, v. 36, n. 1, p. 17-25, 2006.

RAFFESTIN, Claude. Por uma geografia do poder. São Paulo: Ática, 1993. 269 p.

RAMOS, Soraia F. Sistemas técnicos agrícolas e meio técnico-científico-informacional no Brasil. In: SANTOS, M. \& SILVEIRA, M. L. O Brasil: território e sociedade no início do século XXI. Rio de Janeiro: Record, 2001. p. 375-387

SANTOS, Boaventura Sousa. Um discurso sobre as ciências na transição para uma ciência pós-moderna. Estudos Avançados, v. 2, n. 2, p. 46-71, 1988.

SANTOS, Milton; SILVEIRA, María Laura. O Brasil: território e sociedade no início do século XXI. Rio de Janeiro: Record, 2001. 473 p.

SANTOS, Milton. Metamorfoses do espaço habitado. São Paulo: Hucitec, 1988. 124 p.

SANTOS, Milton. Técnica, espaço, tempo: globalização e meio técnico-científico informacional. São Paulo: Hucitec, 1994. 190 p.

SANTOS, Milton. A natureza do espaço: técnica e tempo, razão e emoção. São Paulo: Hucitec, 1996. 308 p.

SANTOS, Milton. . Desenvolvimento econômico e urbanização em países subdesenvolvidos: os dois sistemas de fluxo da economia urbana e suas implicações espaciais. Ciência Geográfica, Edição Especial, p. 78-86, 1997.

SANTOS, Milton. Por uma outra globalização: do pensamento único à consciência universal. Rio de Janeiro: Record, 2000. 174 p.

Trabalho enviado em janeiro de 2010

Trabalho aceito em abril de 2010 